\title{
Integrate Entrepreneurial Thinking into Instrumental Analysis Experiment Teaching
}

\author{
Wang Haifeng ${ }^{1, a}$, Liu Haixue ${ }^{1, b, *}$, Wang Junbin ${ }^{2, ~ c}$, Zhu Wenbi ${ }^{1, d}$ \\ ${ }^{1}$ Center for Agricultural Analysis and Measurement, Tianjin Agricultural University, Tianjin, 300384, China \\ ${ }^{2}$ College of Basic Sciences, Tianjin Agricultural University, Tianjin 300384, China

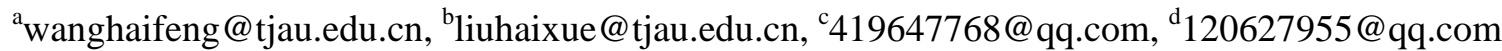 \\ *corresponding author
}

Keywords: entrepreneurship thinking; experimental teaching; instrument analysis experiment

\begin{abstract}
This article attempts to integrate the entrepreneurial thinking into the teaching of the instrument analysis experiment course. Starting with the concept of entrepreneurial thinking, this paper analyzes its importance in the process of instrumental analysis and experiment teaching, and takes the instrument analysis experiment of Tianjin Agricultural University as an example to elaborate the concrete reform scheme.
\end{abstract}

\section{Introduction}

The state of mind determines the state, and the mind determines the behavior. The new era needs new ideas. In the face of this rapidly changing world, the future is unpredictable. What should we teach students as teachers? It's worth thinking about. Starting from the practical teaching idea of "strengthening the foundation, paying attention to practice, cultivating ability and highlighting innovation", the author focuses on the cultivation of innovative practical talents in colleges and universities, the reform of experimental teaching as the foothold, and the student-oriented study as the center. Cultivate ability type college students. Students always have to step into society, engage in different occupations, create different values, not meet the needs of a single course in a university, and then we have to change our studies. Take the initiative to explore the unknown with knowledge, and teach students the ability to cope with change for life. It is necessary to start with the teaching design, which has two kinds of thinking: management thinking and entrepreneurial thinking, entrepreneurship thinking is quality education, is the premise of innovative entrepreneurship education, through the combination of entrepreneurial thinking and instrumental analysis experiment, It is of great significance to make students have the quality and skill of starting a business.

\section{The Concept and Importance of Entrepreneurial Thinking}

How to let students have entrepreneurial thinking? Entrepreneurial thinking is to act first, then to learn the way of thinking focus on learning in action. Someone said entrepreneurial thinking is the spirit of innovation that entrepreneurs possess innovative consciousness and ability to transform it into concrete behavior, which is an important part of comprehensive entrepreneurial quality, and points out that a comprehensive entrepreneurship curriculum system should be constructed. Improve the teacher training system to achieve the goal of entrepreneurship training.

Our teaching methods used to focus on learning first and then on action. In the face of the rapid development of electronic products and the network world, students' acquisition of knowledge is no longer confined to the classroom of teachers, and the amount of information on the Internet is very large. New teaching methods, such as PowerPoint teaching, micro class, admiration class, flipping class and so on, have emerged at the request of the times. The era of teaching that can be done with a piece of chalk and a pad is over.

The most important thing is that entrepreneurial thinking can also actively deal with the negative 
surprises in learning, life, and work, and can transform them into positive and valuable ones to improve self-efficacy.

\section{The Problems of Traditional Management Thinking in The Experimental Teaching of Instrument Analysis}

In recent years, the state has vigorously supported the education of innovative entrepreneurship, but at present, the education of entrepreneurial thinking has not yet formed a system, the curriculum content is relatively poor, simple, the basic concept of entrepreneurial thinking education has not yet formed. Teacher training is urgent because there is a lot of work to be done in the research of students' training goal, training scheme, training system construction, curriculum system construction and so on, so teachers and students' thoughts need to be changed urgently. In the previous instrumental analysis experiment teaching, the traditional management thinking dominated, mainly according to the established syllabus, teaching plan, designated teaching materials for the infusion-type teaching, students accept is the classroom teacher explained, for the instrument principle, structure the knowledge of boring and difficult to understand is very limited, and students have little chance to participate in practice.

\section{Integration of Entrepreneurial Thinking into Instrument Analysis Experiment Teaching Design}

By taking part in the training of entrepreneurship instructors, I think of applying entrepreneurial thinking to the experimental teaching of instrumental analysis. It is necessary to make full use of the present educational technology to solve the difficulties in the experimental teaching of instrument analysis. Combined with animation, multimedia simulation teaching is adopted to make students grasp the principle of method more easily, combined with virtual simulation training platform video, material and animation, so that students can grasp the internal structure and operation of the instrument more intuitively. In the course of teaching, we can promote the combination of virtual, green and simulation experiments with the training and practice in real environment, and improve the effect of experiment teaching.

\subsection{Introduction of New Teaching Techniques.}

The aim of this paper is to carry out new technology training in education and teaching, to make use of modern information technology, to promote the implementation of new classroom teaching models such as Mooc, "micro-class" and "flipping classroom", and to establish a classroom system in which online education and offline education can cooperate with each other. At present, the experimental network platform has been built in the course of instrument analysis, and the corresponding experimental teaching courseware has been made. Students can browse and download at any time through the network to make the teaching of this course vivid and easy to understand. In order to facilitate students' self-study, deeply understand the contents of curriculum and experiment teaching, let students really participate in the teaching interaction, part of the educational resources (teaching staff, high-quality courses, network) are put forward. Courses, courseware, multimedia electronic teaching plans, teaching rules and regulations, experimental equipment, etc. placed on the network server, students change from simple passive teaching of knowledge to active participation and autonomous learning, giving play to students' active initiative.

\subsection{Application of Virtual Simulation Training Platform for Instrument Analysis.}

The teachers participated in the design and development of the "virtual simulation training platform for instrumental analysis", using various means, such as computer and modern network technology, to simulate experimental sites, equipment, instruments and various reagents, to create a pure virtual experimental environment, and to accurately simulate actual experimental state and instruments by providing a simple interface. The operation process is analyzed and evaluated. The 
instrument, the teacher guidance, the teaching content and the students' operation are integrated together, and a virtual simulation laboratory is constructed by the virtual reality technology. The teaching application and research of the system are carried out, and the virtual simulation experiment system is taught in the experiment teaching. The teaching application effect of learning, solve the problem that the big instrument only has one, the student is difficult to use.

\subsection{The Establishment and Practice of the Studio.}

Through the instrument analysis class master skill, establishes the studio pattern. There are mainly college students skills competition studio, agricultural product quality testing service studio, large-scale instrument function development space and agricultural product quality standard R \& D studio. With the studio as the carrier and the actual project as the support, the teaching, scientific research and social service are closely combined to promote the natural integration of teaching and employment, and thus to train applied talents who adapt to the social development. "Studio Mode" combines teaching with practical projects, creates an open and freestyle educational and teaching environment, emphasizes the combination of theory and practice, knowledge and technology, and emphasizes " The teaching idea of "learning by doing" distinguishes the traditional classroom, laboratory teaching and studio mode with its open space, professional orientation of teaching content and sociality of teaching results, and achieves innovative teaching results. Through the opening of the studio, we can maximize the role of existing resources, such as material, financial and human resources; through opening up, students can enter the laboratory as soon as possible, enjoy better quality experimental teaching resources, and participate more in practical projects. Give full play to the entrepreneurial thinking of students.

\section{Summary}

The instrumental analysis experiment teaching will use the modern teaching means and the studio mode of the virtual simulation platform to change the traditional experimental teaching methods and means, take into account the advantages of the virtual experiment and the real experiment, so as to form the "virtual reality combination, the advantage complementation" heuristic, the inquiry instrument analysis experiment teaching. The experiment teaching resources should be used to create the virtual reality combined with the experimental environment, and to guide and encourage students to participate in the whole process of the virtual reality combination experiment. It embodies the students as the main body and the teacher as the leading part, to stimulate the students' interest in experiment and innovation. Work hard, innovate, and develop students' ability to find, analyze, solve problems and communicate and cooperate.

\section{Acknowledgements}

This work was financially supported by the university teacher education reform and innovation guidance development projects of TJAU (20171009 and 20170402) and 2018 innovative and entrepreneurship laboratory project of TJAU.

\section{References}

[1] P Chen. Educational Observation, Vol. 7(2018), p65-67 (in Chinese).

[2] Nendaz M R, Tekian A.Teaching and Learning in Medicine, Vol. 11(1999), p232.

[3] Wenming Shao.Study on Continuing Education,Vol. 1(2017), p21-23 (in Chinese).

[4] Hanfang Chu, Yankong Zhu. Experimental Techniques and Management, Vol. 31(2014), p97-100 (in Chinese).

[5] Chang Sun. Laboratory Research and Exploration, Vol. 31(2012), p85-88 (in Chinese).

[6] Yunlong Liu. Innovation and Entrepreneurship Education, Vol. 6(2016), p76-79 (in Chinese). 